\section{DANDELION}

postgraduate arts journal \& research network

VOLUME 4 NUMBER 2 WINTER 2013
Julia PECK is Senior Lecturer in Photography at University of Roehampton, London. Her doctoral thesis examined the visual construction of the Australian landscape in commercial photographic practices. Her photographic work has been exhibited in the UK and she has contributed images, articles and reviews to Next Level, Source, History of Photography and Journal of Australian Studies; she has also co-edited the Photography, Archive and Memory special issue of photographies (2010).

j.peck@roehampton.ac.uk

Book review

\title{
Petrochemical America
}

by Richard Misrach and Kate Orff

New York, Aperture, 2012, 216 pp., Ł50.00, ISBN 978-I597। I I9II

Julia Peck

Photographic MONOGRAPHS DEPICTING ENVIRONMENTAL DEVASTATION are routinely discussed in terms of the effectiveness of the book's impact on consumer patterns and public policy. Questions usually abound, too, about the effectiveness and morality of the aesthetics of devastation, sometimes referred to as the 'industrial sublime'. ${ }^{1}$ Such questions and observations are pertinent to Richard Misrach and Kate Orff's book Petrochemical America, especially as the authors aim to propose solutions to environmental problems, as well as representing the environmental and social nature of those problems. The book focuses on a geographic area that stretches one hundred and fifty miles along the Mississippi River corridor from Baton Rouge to New Orleans - an area known in colloquial terms as the 'River Road' or 'Cancer Alley'. Their approach stands in contrast to some other publications by photographers depicting environmental devastation and resource exploitation - notably Edward Burtynsky's Manufactured Landscapes, Oil and Australian Minescapes - and Mitch Epstein's American Power, in eschewing the stand-alone image. ${ }^{2}$ Misrach and Orff have undertaken an ambitious project with substantial aesthetic, emotional and educational impact, engaging with the scale of environmental challenges in a complex way that is conceptually and visually satisfying. Their work acknowledges both the magnitude of the changes evidenced to date, and the level of change needed to avert greater environmental and social disasters. What is missing from the book, however, is a discussion of the economic 
models driving environmental degradation and how such models are themselves unsustainable.

The book is split into two sections. The first section contains landscape photographs produced by Misrach in 1998 and 2010: in 1998 Misrach was commissioned by the High Museum in Atlanta for their Picturing the South series, which resulted in a series of photographs depicting the Mississippi and its surrounds. In 2010, the High Museum invited Misrach to revisit the series, prompting further research, photography and a follow-up exhibition. These sets of photographs are beautifully printed and are often accompanied by extended captions. The 2010 revision prompted Misrach to investigate alternative ways of living and environmental problem solving, resulting in a collaboration with Kate Orff, a landscape architect and associate professor at Columbia University. Orff's contribution occupies the second section of the book: a series of texts, diagrams and designs incorporating Misrach's photographs, together with drawings and statistical data providing information regarding the consumption of oil in America. This far reaching and analytical section outlines the impact of oil on the environment from its extraction, processing and distribution, to the uses and effects of oil-related products and the influences these activities have on the complex yet fragile communities in the Mississippi Delta. Acknowledgement is also made of world-wide factors such as outsourcing labour to the developing world and climate change. This part of the book is both visually and informationally rich, demonstrating the interconnecting influences of the petrochemical industry on virtually all aspects of American life.

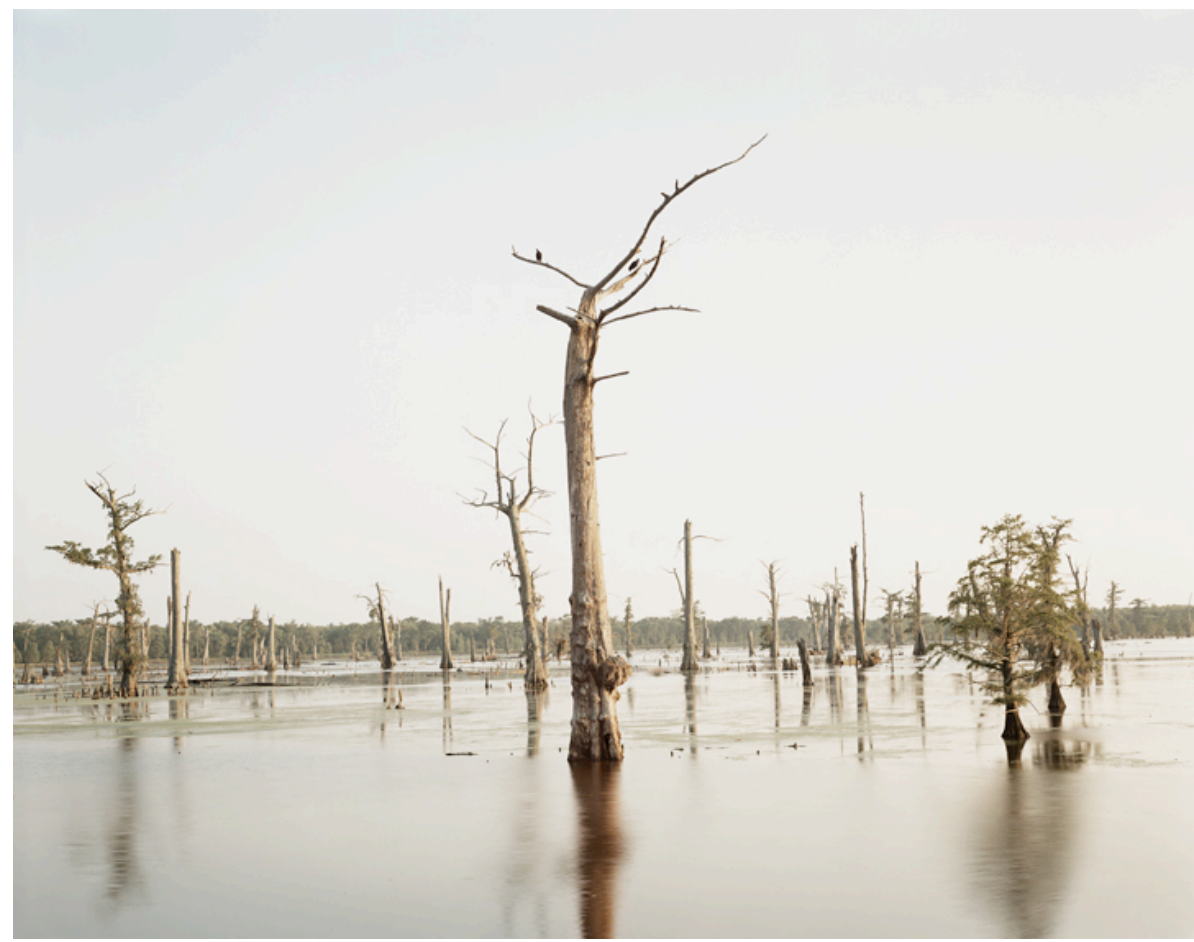

Figure I. Cypress Swamp, Alligator Bayou, Prairieville, Louisiana, 1998, from Petrochemical America, photographs by Richard Misrach, Ecological Atlas by Kate Orff (Aperture 2012) (C) Richard Misrach, courtesy of Pace/MacGill Gallery, New York; Fraenkel Gallery, San Francisco; and Marc Selwyn Gallery, Los Angeles. 
The photographs will feel familiar to those who have followed Misrach's career. His trademark 'straight' photographs depict parts of the landscape from ground level, showing flooded waste sites, the Mississippi River, views of petrochemical processing plants, photographs of preserved historical plantations and slave dwellings, general views of roadsides and churches and photographs of environmental degradation such as this damaged cypress swamp [Figure 1]. The photographs are beautiful and occasionally troubling, especially in the instance of flooded disposal sites, but there is also a familiar sense of the banal and the everyday pervading the book. The photographs, whilst depicting scenes that are familiar, are rendered in very fine detail with attention to composition, light and time of day. Although the Mississippi Delta has a rich and diverse culture and is strongly associated with narrative journeys, ${ }^{3}$ Misrach, more frequently associated with landscapes in the American west, here shows his ability to engage with less heroic and less dramatic scenes. His photographs rarely include people, and this absence gives the photographs an air of melancholic abandonment, even though these landscapes remain populated. Although I miss the presence and voices of people affected by the various and multiple aspects of the petrochemical industry, the view of the landscape remains resolutely human, at ground level. ${ }^{4}$ The focus here, whilst eschewing the personal, is on the visual appearance of the landscape and how looking at and engaging with it can prompt reflection on the state of the environment and the multiple complex factors that affect it, as well as on how the landscape, in turn, affects multiple lives.

Similarly to many photographers working with important issues, Misrach has not left the images to speak alone. Indeed, all photographers have to engage on some level with the potential polysemy of photographs, and Misrach avoids leaving the viewer with an ambiguously aesthetic experience of these places through his use of text. All images have captions informing the reader about the location, the main object of the photograph and the year the photograph was made. Some of the photographs are accompanied by longer captions, which provide greater insight into the significance of the site or the environmental/human devastation being witnessed. In some instances the caption offers information on poisoning and pollution and, in others, on the social and physical impact of various petrochemical processing plants. Misrach further acknowledges the complex social dynamics that have formed in 'Cancer Alley' and which feature significantly in contemporary life, including the practice of religion, the multiple diasporas and communities resulting from displacements associated with the slave era and later, and the poverty of many people living in the region. Although the photographs are static, a sense of dynamism arises from the images and this information. The first part of the book also contains a postscript - this is where Misrach's photographs from 2010 appear. In keeping with his trademark style, Misrach adds the topics of new-build housing (with their use of petrochemically derived plastics), community resistance to further petrochemical incursion, parking lots, and the Deepwater Horizon spill to the already considerable body of work.

The small number of new photographs here is a little disappointing. Surely there was more to say about recent events in the region or the Deepwater Horizon spill itself? Perhaps so, but other photographers have made work of this spill and Misrach's strategy seems to be to remain allusive - his photographs suggest that it is the invisible or overlooked aspects of the petrochemical industry that are of importance here; the ways in which poisons, chemicals, and our ways of living are impacting on the land and underpinning the very fabric of our existence. The interconnectedness of these processes is 
strongly hinted at in his work, such as in Figure 2, where sugar cane, a crop dependent upon petrochemicals, and the petrochemical processing plant itself exist side by side. Orff extends these observations in her work, making explicit the ways in which oil is fundamental to American notions of identity, such as in Figure 3. Here she makes explicit American ideas about the right to space, the suburban dream, and the wholesale consumption of goods and processed food, in order to illustrate the dependence on the petrochemical industries that underpins American life.

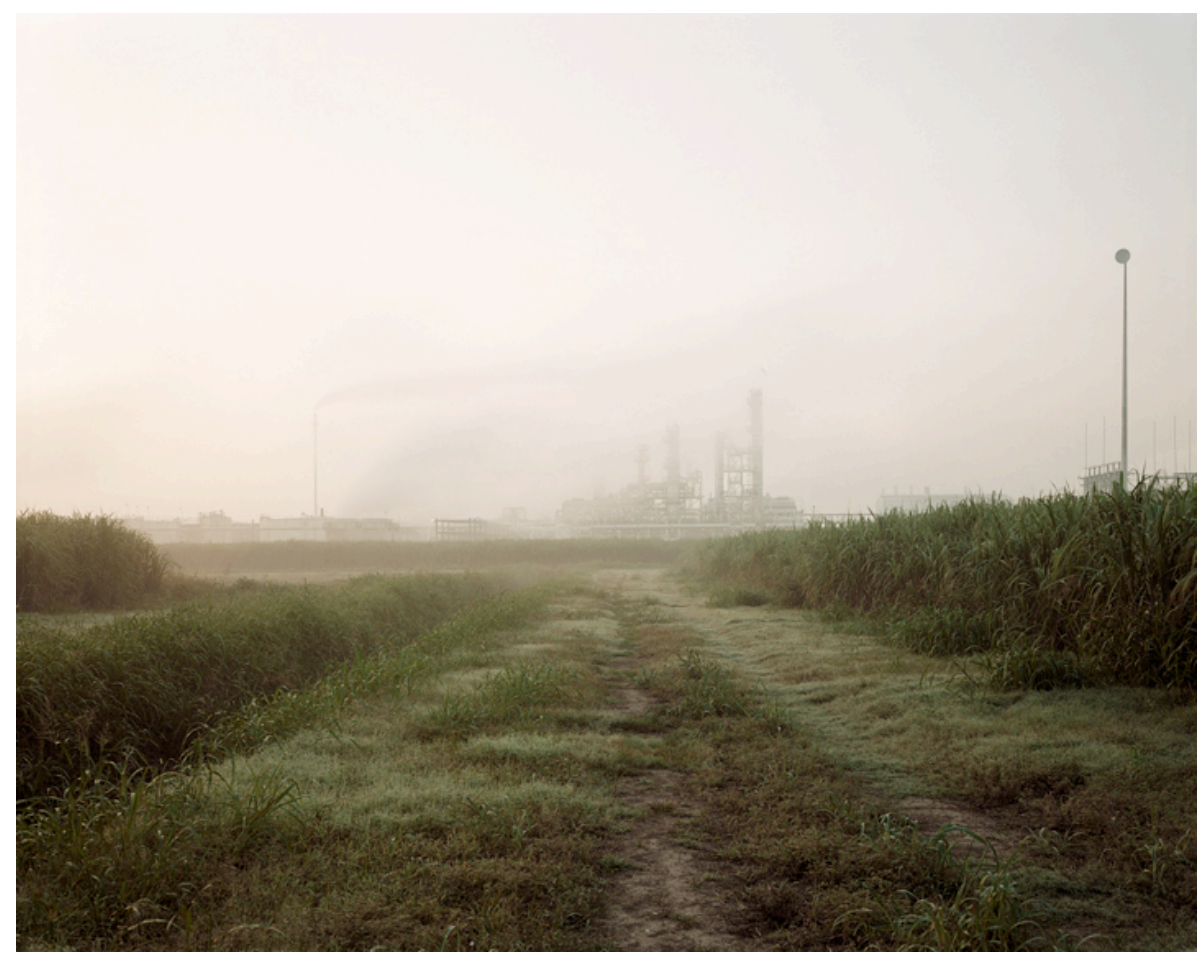

Figure 2. Sugar Cane and Refinery, Mississippi River Corridor, Louisiana, 1998, from Petrochemical America (Aperture 2012) (C) Richard Misrach, courtesy of Pace/MacGill Gallery, New York; Fraenkel Gallery, San Francisco; and Marc Selwyn Gallery, Los Angeles

What is perhaps surprising, then, given that ideologies (in the form of nation-state identities and their relationship to patterns of consumption and living) are tacitly touched upon, is the absence of a more rigorous discussion of sustainability. Although the book does not contain a statement about its underpinning philosophy, sustainability is repeatedly referred to in both the introduction and in Orff's section of the book. A discussion of sustainability would probably have complicated the book but would have exposed how such notions are frequently used to sustain businesses rather than addressing longterm environmental human and social needs at community and global levels. ${ }^{5}$ Sustainability is therefore a problematic and contradictory notion to rely upon and probably limited as a means of controlling climate change and environmental degradation. Although sustainability does have its supporters, and has been linked to photographic practices before, both Misrach and Orff seem to have taken it for granted that readers will feel that sustainability is an appropriate discourse to support. ${ }^{6}$ While the complex histories of 'Cancer Alley' are acknowledged, there is no discussion of how capitalism and the drive to economic growth might challenge notions of sustainability. Despite the benefits of engaging with sustainability as a discourse (for example, the avoidance of notions of good/bad consumption, the active examination of 'footprint' and 
'impact', and the consequences of choices), I find it troubling that the authors have opted for this approach without discussion or explanation.

Other aspects of the book are much more explicit: the power and financial magnitude of corporations such as Royal Dutch Shell, Exxon Mobil, BP, Chevron and Total (five of the top six world's largest corporations as of 2009, all of which are petrochemical companies) are acknowledged. These corporations are so large and profitable that they rival the wealth and power of nation states; they also hold considerable influence through lobbying. ${ }^{7}$ But Orff stops short of acknowledging the danger of these global corporations for the environment around the globe. Orff's text, then, points towards the tangled lives of state and finance and the influence of larger corporations (particularly in regard to lobbying power) but falls short of addressing the capitalist system that enabled this problematic situation to emerge: the overriding power of global corporations that have put neighbourhoods, regions and the climate of the globe (and hence the global population) into longer term jeopardy through potential food shortages and the physically reducing landmass available for habitation and cultivation.

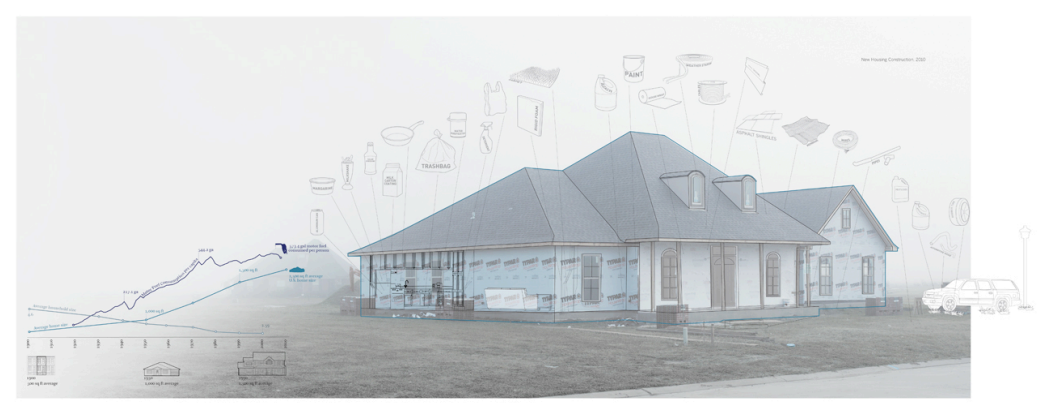

Figure 3. Bigger, Farther, Filled with More Stuff, from Petrochemical America, photographs by Richard Misrach, Ecological Atlas by Kate Orff (Aperture 20I2) OSCAPE

While the book avoids an explicit engagement with sustainability and the impact of capitalism, it does at least acknowledge the importance of global capital. The book ends with a 'Glossary' that aims to explain some of the terms used and offers ideas for what readers, or organisations, can do. Some of this is directed towards individual action (consuming less, taking public transport, walking etc.) and some towards community-wide activities (such as starting a 'library' of power tools and other objects; using action networks). There are suggestions regarding citizen action, environmental and urban planning that promote larger collective and state-led action, but entries proposing the curtailing of growth, with the exception of the 'smart growth' entry, are notably limited. Strategies for curtailing corporate power and influence would surely warrant further discussion in a book such as this, but perhaps they were considered unrealistic by its authors.

Although I am disappointed that the book is not rigorously analytical in relation to its underpinning ideologies, it does raise some pertinent questions. It is, after all, not a manifesto, a book of theory or a political crusade, but a collaborative artists' monograph. As such it is a powerful explication of the aesthetic, social and environmental impact of the petrochemical industry in America. It acknowledges the worldwide impact of American patterns of consumption and how the communities of 'Cancer Alley' bear the physical brunt of the industrial processing of waste and pollution through ill health and declining standards of living (notably through the lack of access to health care 
and through the erosion of communities). It strikes me that this is a more rigorous, accessible and effective book than many other photographic renditions of environmental devastation and it remains visually compelling. But given the urgency of our plight, and our collective unwillingness to address change, the question of whether this book is 'enough' remains very much open. What constitutes 'enough', and how will collective change become widespread and effective? After reading this book, I am less hopeful that individual-level consumer changes will be effective unless change is led and implemented by our collective nations, unhampered by global corporate greed.

\section{Roehampton University}

\section{Notes}

$1 \quad$ Liz Wells, 'Points of Departure: Currencies of the post-industrial sublime', in Futureland Now, John Kippin and Chris Wainwright (Plymouth: University of Plymouth Press, 2012), pp. 31-44 (p. 33).

2 Burtynsky's photographs have attracted considerable discussion regarding ethics and impact over recent years. See, for example: Lori Pauli, Manufactured Landscapes: The Photographs of Edward Burtynsky (Ottawa: National Gallery of Canada in association with Yale University Press, 2009); Joshua Schuster, 'Between Manufacturing and Landscapes: Edward Burtynsky and the Photography of Ecology', Photography and Culture, 6 (2013), pp. 193-212.

Anne Wilkes Tucker, 'and empty grows every bed..., Alec Soth, Sleeping by the Mississippi (Gottingen: Steidl, 2008), unpaginated.

This is in contrast to other practices where the corporate scale of oil extraction requires corporate co-operation and finance, such as in the production of aerial views. Aerial views are discussed in Schuster, pp. 193-212, p. 202, p. 207 and p. 210 Rob Krueger and David Gibbs, The Sustainable Development Paradox: Urban Political Economy in the United States and Europe (London and New York: Guilford Press, 2007), pp. 41-65.

Schuster, p. 203; Paul Starr 'Ethical Consumption, Sustainable Production and Wine', in Ethical Consumption: A Critical Introduction, ed. by Tania Lewis and Emily Potter (London and New York: Routledge, 2011), pp. 131-140 (p. 139).

Richard Misrach and Kate Orff, Petrochemical America, (New York: Aperture, 2012), p. 123.

\section{Works Cited}

Epstein, Mitch, American Power (Gottingen: Steidl, 2009)

Mitchell, Michael, Australian Minescapes: Edward Burtynsky (London:

Flowers East, 2009)

Pauli, Lori, Manufactured Landscapes: The Photographs of Edward Burtynsky

(Ottawa: National Gallery of Canada in association with Yale

University Press, 2009)

Schubert, Marcus and Paul Roth, Edward Burtynsky: Oil (Gottingen: Steidl, 2009) 